\title{
Study of Internet Use Characteristics, Perceived Stress, and Internet Addiction among First-year Medical Students of Jamnagar, Gujarat, India
}

\author{
Vishal K Patel
}

\begin{abstract}
Background: Internet addiction increases the stress level and interferes with the academic performance and other activities in college students. The objective was to examine the relation of internet use characteristics and perceived stress in internet addiction among first-year medical students.

Materials and methods: This was a cross-sectional and observational study of 200 first-year students of medical college, Jamnagar. Patterns of internet use and socioeducational data were collected. Internet addiction test (IAT) was used to assess the internet addiction. Perceived stress scale (PSS) was utilized to assess the stress level. The data were analyzed using appropriate statistics.

Results: Out of total 172 participants, $5.73 \%$ of students had internet addiction. More than half of the students with internet addiction were using internet for 5 years or more and almost everywhere, spending more money, and using multiple gadgets for internet. More than $85 \%$ of the students with internet addiction did not perform any daily exercise/sports, were spending more than 2 hours in a day, and had high levels of perceived stress. The distribution of total duration of internet use, time and money spent on internet, gadgets used for internet, perceived stress, and internet addiction was also found to be statistically significant using multiple logistic regression analysis.

Conclusion: Internet usage with multiple gadgets and spending more time, for longer duration ( $>5$ years), were correlates of internet addiction in college students. Students with internet addiction perceived high level of stress.

Keywords: College students, Internet addiction, Perceived stress.

Indian Journal of Private Psychiatry (2019): 10.5005/jp-journals-10067-0037
\end{abstract}

\section{INTRODUCTION}

Across the globe, the trend of using smart phone and internet is increased among the college students in last few years. Nowadays, they are using internet for different purposes like gathering information, transactions, communication, entertainment, and gaming, etc. There have been serious concerns about excessive internet use and related problems in students. Although internet addiction is not included as a clinical disorder in latest edition of Diagnostic and Statistical Manual of Mental Disorder and International Classification of Disease, since many years, few researchers have worked on addictive potential of internet use and tried to define internet addiction. It is a type of behavioral addiction and it includes core features like salience, mood modification, tolerance, withdrawal, conflict, and relapse. ${ }^{1-3}$

The prevalence of internet addiction varies from $0.7 \%$ to $18.6 \%$ among the college students. Many studies found that the college students as the group are highly susceptible to internet addiction. ${ }^{2-11}$ Globally, with the rise of new-generation smart phone and easy availability of internet, the risk of "internet addiction" is emerging as a pandemic health problem in young adults. ${ }^{3}$ Research studies suggests that the internet addiction is associated with loneliness, lower self-esteem, poor academic performance, high level of stress, anxiety, depression, and other mental health problems in students. ${ }^{4-14}$ Considering the heavy internet use among the college students, it is important to analyze the internet use among the first-year health professional undergraduates. The objectives were to study the proportion of undergraduates with internet addiction and to assess the relation between internet addiction and psychological distress.
Department of Psychiatry, Dr MK Shah Medical College and Research Centre and SMT SMS Multispeciality Hospital, Ahmedabad, Gujarat, India

Corresponding Author: Vishal K Patel, Department of Psychiatry, Dr MK Shah Medical College and Research Centre and SMT SMS Multispeciality Hospital, Ahmedabad, Gujarat, India, Phone: +91 9228249767, e-mail:dr.vk63@yahoo.com

How to cite this article: Patel VK. Study of Internet Use Characteristics, Perceived Stress, and Internet Addiction among First-year Medical Students of Jamnagar, Gujarat, India. Ind J Priv Psychiatry 2019;13(2):44-47.

Source of support: Nil

Conflict of interest: None

\section{Materials and Methods}

This was a 3 month, cross-sectional, observational study conducted from October 2017 to December 2017. First-year MBBS students of the college were selected as participants. They were explained the study objectives, and their written informed consent was obtained. Every year, a total of 200 students are admitted in firstyear MBBS. We have approached the whole class and included all of them. The students that refused to participate in the study were excluded. Study was approved by Institutional Ethical Committee of MPSGMC, Jamnagar.

An awareness lecture on internet addiction was arranged for the first-year students. The students were requested to fill up a semistructured proforma specifically designed for the study. 
The participants were assessed for internet addiction and perceived stress using the tools as described below.

\section{Tools}

A semistructured proforma that included details of age, gender, educational qualification of parents, computer ownership, place of access (home/hostel, and college, etc.), and time spent of internet, money spent on internet use, gadgets use for internet, time of internet use, regular daily exercise/sports was used.

\section{Internet Addiction Test}

It is a 20 -item 5 -point Likert scale that measures the severity of self-reported compulsive use of the internet. A total score of internet addiction test (IAT) ranges from 0 to 100. Participants with average online use have a score of 20-49, those with a score of 50-79 are likely to have occasional or frequent problems and a score of $>79$ in those with significant problems due to internet use. Internet addiction test analyzes six factors-salience, excessive use, neglecting work, anticipation, lack of control, and neglecting social life. These factors have a good internal consistency (0.88) and concurrent validity, with salience being the most reliable. The internal reliability of the scale is 0.93 . For the purpose of this study, participants scoring 50 or above in IAT were considered to have internet addiction., ${ }^{1,5}$

\section{Perceived Stress Scale}

It is a 10-item scale individual item based on Likert scale ranging from 0 to 4 . Participants with scores ranging from 0 to 13 would be low stress, 14 to 26 would be moderate stress, and 27 to 40 would be high perceived stress. Perceived stress scale (PSS) exhibited satisfactory psychometric property. ${ }^{6}$

\section{Statistical Analysis}

Data collected were subjected to appropriate descriptive statistics using frequencies, percentages; of different variables were calculated. Chi-square test was used for qualitative data. The $p$ value of $<0.05$ was considered statistically significant. Binary logistic regression analysis was used to calculate odds ratio. Statistical Package for the Social Sciences (SPSS) version 15 was applied to analyze the data.

\section{Results}

Out of total 200 participants, 172 students completed their proforma and were included for final analysis. Among them, 5.73\% of students using internet had satisfied the criteria for internet addiction. The mean age of students was 18.3 years. More than half of the students with internet addiction were using internet for 5 years or more and almost everywhere, spending more money, and using multiple gadgets for internet. More than $85 \%$ of the addicted students did not perform any daily exercise/sports, spending more than 2 hours in a day, and perceived high level of stress. The distribution of total duration of internet use, time and money spent on internet, gadgets used for internet, perceived stress, and internet addiction was statistically significant using binary logistic regression analysis (Tables 1 and 2).

Table 1: Association pattern of internet usage and psychological stress with the internet addiction

\begin{tabular}{|c|c|c|c|c|c|}
\hline \multirow[b]{2}{*}{ Variables } & & \multicolumn{2}{|c|}{ Internet use } & \multirow[b]{2}{*}{ Chi-square } & \multirow[b]{2}{*}{$p$ value } \\
\hline & & $\begin{array}{l}\text { Non-addict } \\
(n=142)(\%)\end{array}$ & $\begin{array}{l}\text { Addict } \\
(n=30)(\%)\end{array}$ & & \\
\hline \multirow[t]{2}{*}{ Gender } & Male & $74(52.11)$ & $21(70)$ & 3.205 & 0.73 \\
\hline & Female & $68(47.88)$ & $9(30)$ & & \\
\hline \multirow[t]{3}{*}{ Father's education } & Below UG & $33(23.23)$ & $7(23.33)$ & 0.423 & 0.809 \\
\hline & UG & $68(47.88)$ & $16(53.33)$ & & \\
\hline & UG and above & $41(28.87)$ & $7(23.33)$ & & \\
\hline \multirow[t]{3}{*}{ Mother's education } & Below UG & $48(33.80)$ & $11(36.66)$ & 0.123 & 0.940 \\
\hline & UG & 69 (48.59) & $14(46.66)$ & & \\
\hline & UG and above & $25(17.60)$ & $5(16.66)$ & & \\
\hline \multirow[t]{2}{*}{ Gadgets used } & Mobile & $128(90.14)$ & $10(33.33)$ & 50.395 & 0.001 \\
\hline & Mobile, laptop, and others & $14(9.85)$ & $20(66.66)$ & & \\
\hline \multirow[t]{2}{*}{ Place of prominent use } & Hostel/home & $128(90.14)$ & $11(36.66)$ & 45.677 & 0.001 \\
\hline & Almost everywhere & $14(9.85)$ & $19(63.33)$ & & \\
\hline \multirow[t]{2}{*}{ Time spent/day } & $<2$ hours & $132(92.95)$ & $4(13.33)$ & 94.883 & 0.001 \\
\hline & $>2$ hours & $10(7.04)$ & $26(86.66)$ & & \\
\hline \multirow[t]{3}{*}{ Maximum time spent/day } & Entertainment & $73(51.40)$ & $11(36.66)$ & 5.386 & 0.68 \\
\hline & Social media & $56(39.43)$ & $12(40)$ & & \\
\hline & Academic & $13(9.15)$ & $7(23.33)$ & & \\
\hline \multirow[t]{2}{*}{ Money spent/month } & $<300$ rs & $139(97.88)$ & $14(46.66)$ & 55.199 & 0.001 \\
\hline & $>300 \mathrm{rs}$ & $3(2.11)$ & $16(53.33)$ & & \\
\hline \multirow[t]{2}{*}{ Total duration of internet use } & $<5$ years & $136(95.77)$ & $11(36.66)$ & 69.658 & 0.001 \\
\hline & $>5$ years & $6(4.22)$ & $19(63.33)$ & & \\
\hline \multirow[t]{2}{*}{ Regular exercise/sports } & Absent & $113(79.57)$ & $26(86.66)$ & 0.803 & 0.370 \\
\hline & Present & $29(20.42)$ & $4(13.33)$ & & \\
\hline \multirow[t]{2}{*}{ Perceived stress in last month } & Low to moderate & $112(78.87)$ & $4(13.33)$ & 48.451 & 0.001 \\
\hline & High & $30(21.12)$ & $26(86.66)$ & & \\
\hline
\end{tabular}


Study of Internet Use Characteristics, Perceived Stress, and Internet Addiction among First-year Medical Students

Table 2: Binary logistic regression analysis of variables related to internet addiction

\begin{tabular}{|c|c|c|c|c|c|c|}
\hline \multirow{2}{*}{ Variables } & & \multirow[b]{2}{*}{ Internet addiction $(n=30)(\%)$} & \multirow[b]{2}{*}{ Odds ratio } & \multirow[b]{2}{*}{$p$ value } & \multicolumn{2}{|c|}{ 95\% confidence interval } \\
\hline & & & & & Lower & Upper \\
\hline \multirow[t]{2}{*}{ Total duration of internet use } & $<5$ years & $11(36.66)$ & 1 & 0.018 & 1.59 & 14.13 \\
\hline & $>5$ years & $19(63.33)$ & 1.492 & & & \\
\hline \multirow[t]{2}{*}{ Time spent/day } & $<2$ hours & $4(13.33)$ & 1 & 0.001 & 5.34 & 42.85 \\
\hline & $>2$ hours & $26(86.66)$ & 4.763 & & & \\
\hline \multirow[t]{2}{*}{ Gadgets used } & Mobile & $10(33.33)$ & 1 & 0.001 & 4.44 & 40.251 \\
\hline & Mobile and other & $20(66.66)$ & 4.261 & & & \\
\hline \multirow[t]{2}{*}{ Perceived stress } & No/mild & $4(13.33)$ & 1 & 0.002 & 3.77 & 28.23 \\
\hline & High & $26(86.66)$ & 3.217 & & & \\
\hline \multirow[t]{2}{*}{ Money spent } & $<300$ rs & $14(46.66)$ & 1 & 0.120 & 0.72 & 8.98 \\
\hline & $>300 \mathrm{rs}$ & $16(53.33)$ & 2.54 & & & \\
\hline \multirow[t]{2}{*}{ Place of prominent use } & Home/hostel & $11(36.66)$ & 1 & 0.601 & 0.16 & 21.88 \\
\hline & Everywhere & $19(63.33)$ & 1.915 & & & \\
\hline
\end{tabular}

\section{Discussion}

Globally, many studies have been conducted on internet addiction among the health professional students. This study primarily focuses on first-year undergraduate students of MBBS. Overall $5.73 \%$ of students had internet addiction in this study, which is in accordance with the many studies using Young's IAT. Some studies have reported higher and some has reported lower prevalence of internet addiction. The variation in prevalence rate is due to difference in materials and methods of studies. ${ }^{4-11}$ Internet addiction is more commonly seen in male than female but there was no significant association found between gender and internet addiction in this study. This finding was consistent with the Indian study among MBBS students. ${ }^{9}$ However, some studies found definite association between male gender and internet addiction. ${ }^{7,10}$ This might due to different motivation and behavior for internet addiction between males and females.

The patterns of internet use are varied among the students. In this study, students with internet addiction were spending more time and money than their non-addict counterparts. Majority of the students with internet addiction were using internet for more than 5 years. Although mobile phone was the most preferred gadget for using internet, students with internet addiction were using multiple gadgets for internet compared to non-addict. These findings corroborates with the Indian studies among the health professional students. ${ }^{8}$

In the present study, majority of students with internet addiction did not perform any regular daily exercise and had high level of perceived stress. Similar studies from India and abroad have found that students with internet addiction showed reduced subjective happiness. ${ }^{9,10}$ The present results are also consistent with those studies that reported a strong correlation between stress and internet and smart-phone addiction. ${ }^{11,12}$ Higher level of internet addiction and stress in medical students might be due to length of medical course in India including internship, rural services, and further years of postgraduate education with burden of fee structures posing significant financial problems. Many students face a completely new environment, staying away from home, and with new peers and teachers. Parents and relatives of students have high expectations about their academic performances and future careers, adding to stress level for them. ${ }^{13,14}$
There is a deficit in the phenomenological understanding and treatment of internet addiction. First-year MBBS is a transition period from school to college. It should be considered as a vulnerable time for their whole professional career. Healthy internet usage behaviors, social skill training, strengthening positive coping skills, and modes of seeking help should be included in their foundation course. Screening of students to identify addictive behaviors should require for those who report psychological distress.

\section{ConClusion}

Internet addiction in first-year MBBS students is serious and emerging health issue. It is more common in those students who are spending more time and money for internet, started using internet early in adolescent age, and using multiple gadgets for internet. Psychological distress is more common in students with internet addiction. Awareness lectures about problematic internet usage and its consequences should be included in foundation course. Early identification and intervention for internet addiction in first-year students would benefit their whole professional carrier.

\section{Limitation of the Study}

Study includes the sample from the single college. Large-scale prospective studies about internet addiction will require supporting the study findings in the health professional undergraduates.

\section{Acknowledgments}

The authors are thankful to the medical students for their cooperation and to Community Medicine Department for statistical analysis.

\section{References}

1. Young KS. Internet addiction: the emergence of a new clinical disorder. Cyberpsychol Behav 1998;1(3):237-244. DOI: 10.1089/ cpb.1998.1.237.

2. Christakis DA, Moreno MM, Jelenchick $L$, et al. Problematic internet usage in us college students: a pilot study. BMC Med 2011;9:77. DOI: 10.1186/1741-7015-9-77.

3. Christakis DA. Internet addiction: a 21st century epidemic? BMC Med 2010;8:61. DOI: 10.1186/1741-7015-8-61.

4. Lin SS, Tsai CC. Sensation seeking and internet dependence of Taiwanese high school adolescents. Comput Human Behav 2002;18:411-426. DOI: 10.1016/S0747-5632(01)00056-5. 
5. Widyanto L, McMurran M. The psychometric properties of the internet addiction test. Cyberpsychol Behav 2004;7(4):443-450. DOI: 10.1089/ cpb.2004.7.443.

6. Cohen S, Kamarck T, Mermelstein R. A global measure of perceived stress. J Health Soc Behav 1983;24(4):385-396. DOI: 10.2307/2136404.

7. Anderson KJ. Internet use among college students: an exploratory study. J Am Coll Health 2001;50(1):21-26. DOI: 10.1080/07448480109595707.

8. Srijampana VVGR, Endreddy AR, Prabhath K, et al. Prevalence and patterns of internet addiction among medical students. Med J Dr DY Patil Univ 2014;7(6):709-713. DOI: 10.4103/0975-2870.144851.

9. Suresh VC, Silvia WD, Kshamaa HG, et al. Internet addictive behaviors and subjective well-being among 1st-year medical students. Arch Ment Health 2018;19(1):24-29. DOI: 10.4103/AMH.AMH_3_18.
10. Çardak M. Psychological well-being and internet addiction among university students. Turk Online J Educ Tech 2013;12(3):10-13.

11. Ha J, Ahn H. Multiple mediator effect of metacognition on the relation of perceived stress, anxiety and generalized problematic internet use. Korean J Counsel Psychotherapy 2013;25(2):251-273.

12. Lee JS. The effect of interpersonal relationship on internet addiction level of university students: stress coping strategies as mediating variable. Korean J Youth Counsel 2012;20(2):115-134.

13. Datar MC, Shetty JV, Naphade NM. Stress and coping styles in postgraduate medical students: a medical college-based study. Indian J Soc Psychiatry 2017;33(4):370-374. DOI: 10.4103/ijsp.ijsp_59_16.

14. Cherkil S, Gardens SJ, Soman DK. Coping styles and its association with sources of stress in undergraduate medical students. Indian J Psychol Med 2013;35(4):389-393. DOI: 10.4103/0253-7176.122235. 